\title{
Calcium Looping technology demonstration in industrial environment: the CLEANKER project and status of the CLEANKER pilot plant
}

\author{
Martina Fantini ${ }^{*}$, Maurizio Spinelli ${ }^{1}$, Francesco Magli $^{2}$, and Stefano Consonni ${ }^{1,2}$ \\ ${ }^{1}$ Laboratorio Energia e Ambiente Piacenza (LEAP s.c.a r.l.) \\ ${ }^{2}$ Politecnico di Milano, Department of Energy, 20156 Milano, Italy
}

\begin{abstract}
The CLEANKER (CLEAN clinKER production by calcium looping process) project got EC support from October 2017 to September 2021 under the Horizon 2020 call LCE 29 - 2017. CLEANKER (www.cleanker.eu) aims at demonstrating at TRL7 (Technology Readiness Level) the Calcium Looping (CaL) concept in a configuration highly integrated with the cement production process, making use of entrained flow reactors.
\end{abstract}

\begin{abstract}
There are currently no feasible methods to produce clinker, and thus cement, without releasing $\mathrm{CO}_{2}$ from $\mathrm{CaCO}_{3}$, and, given the lifetime of a cement plant, the technologies to be developed have to be retrofittable. In addition to oxyfuel combustion and post-combustion solvent-based capture technologies, which have attracted most of the research efforts up to now, Calcium Looping is recognized as another very promising emerging technology for $\mathrm{CO}_{2}$ capture in cement plants.
\end{abstract}

The core activity of the project is the design, construction and operation of a $\mathrm{CaL}$ demonstration system including the entrained-flow carbonator (the $\mathrm{CO}_{2}$ absorber) and the entrained-flow oxyfuel calciner (the sorbent regenerator). This demonstration system, connected to the Buzzi Unicem kiln of the Vernasca cement plant (Italy), will capture the $\mathrm{CO}_{2}$ from a portion of the flue gases of the kiln, using as $\mathrm{CO}_{2}$ sorbent the same raw meal that is used for clinker production.

The CLEANKER implementation plan spans four years from October 2017 to September 2021.The project is in its crucial phase: the erection of the demo plant is going to be completed by the end of August 2020 and the experimental campaigns will start immediately after.

\footnotetext{
*Corresponding author: martina.fantini@polimi.it
} 


\section{Introduction}

The CLEANKER project (Clean clinker production by calcium looping process), is a four-year European research project for $\mathrm{CO}_{2}$ capture (CCS / U - Carbon Capture and Storage / Utilization), funded under the Horizon 2020 framework program. CLEANKER is an international partnership comprising 13 organisations (Fig. 1), was officially launched on 1st October. 2017 at the Piacenza headquarters of Politecnico di Milano and sees LEAP as coordinator.

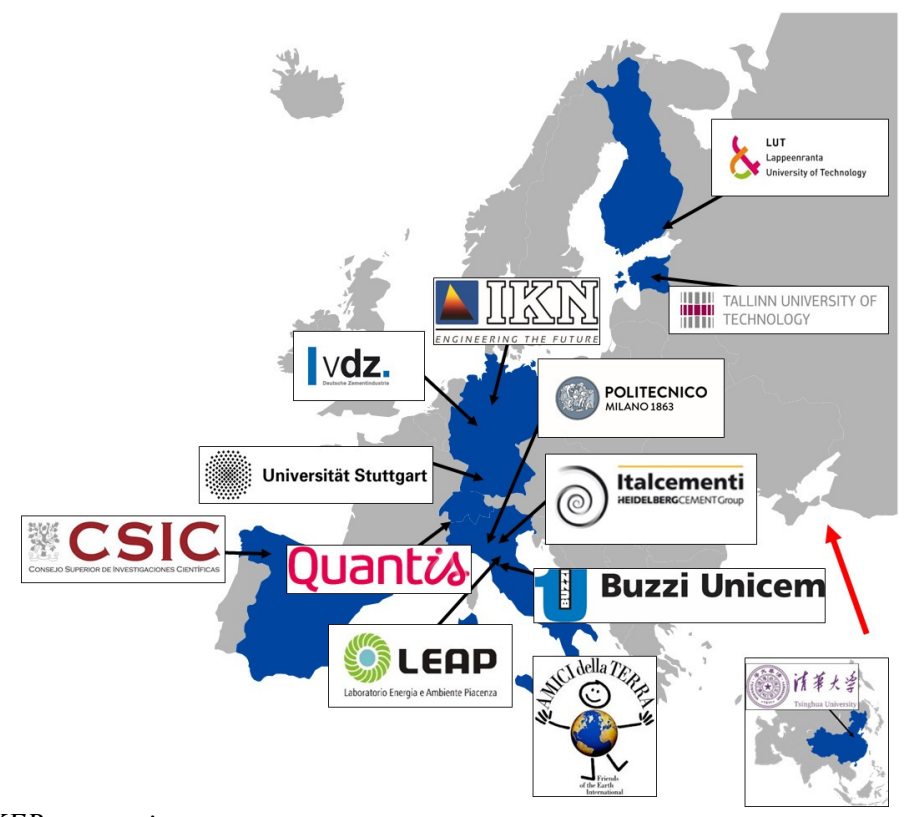

Fig. 1: CLEANKER consortium

The project is an ambitious and fascinating initiative which, if the expectations are confirmed, could represent an important innovation for the cement sector towards an even greater environmental sustainability of the production process.

The cement industry is responsible for about $27 \%$ of global anthropogenic $\mathrm{CO} 2$ emissions from industrial sources worldwide and for 6 to $7 \%$ of global anthropogenic CO2 emissions. Cement is a crucial material for the future construction of sustainable infrastructure and buildings, but the manufacturing of its main constituent (clinker) is $\mathrm{CO} 2$ intensive. Furthermore, most of cement-related $\mathrm{CO} 2$ emission (around 60\%) is unavoidable, because it is generated during the calcination of limestone, the irreplaceable raw material needed to produce clinker. The residual $40 \%$ is associated to the combustion of fuels and to the production of electric power needed in the cement manufacturing process (from quarry to cement dispatch). For these reasons, the decarbonisation of the cement industry is a key factor in achieving the main objective of the 1.5DS scenario (net zero emissions by 2050), but the production of carbon neutral clinker is not feasible without the implementation of carbon capture systems, therefore, the deployment of efficient carbon capture technologies must be selected and realized at large scale in a relatively short period of time.

The aim of the research is to verify the possibility of "capturing" the carbon dioxide generated during the cement production cycle, avoiding its release into the atmosphere, thus pursuing the ultimate goal of helping to contain the greenhouse effect. The capture of $\mathrm{CO}_{2}$, associated with the subsequent storage phase, is a key process for the European Union's 
strategies for containing greenhouse gas emissions. Once captured, in fact, thus suitably isolated as a separate flow downstream of the production process, carbon dioxide can be stored in appropriate geological sites or used as a "raw material" for the synthesis of basic chemicals or fuels. The technology to reduce greenhouse gas emissions in the cement industry will use the principle of "Calcium looping" $(\mathrm{CaL})$. is a regenerative process that takes advantage of the capacity of calcium oxide-based sorbents to adsorb $\mathrm{CO}_{2}$ at high temperatures $\left(600-700^{\circ} \mathrm{C}\right)$. The integrated $\mathrm{CaL}$ process is divided into two basic steps: (1) the limestone calcination is achieved in an oxy-fired reactor (calciner) operating at 900$920^{\circ} \mathrm{C}$, which makes the $\mathrm{CaO}$ available for both the rotary kiln and the $\mathrm{CaL}$ process, and releases a gas stream of nearly pure $\mathrm{CO}_{2} ;(2)$ the $\mathrm{CO}_{2}$ contained in the rotary kiln exhaust gases is separated by $\mathrm{CaO}$ conversion in a second reactor (carbonator) operating at 600$700^{\circ} \mathrm{C}$. This highly integrated $\mathrm{CaL}$ process configuration enables $\mathrm{CO}_{2}$ capture with an efficiency target over $90 \%$ and high-energy efficiency. The overall energy consumption can be kept low by proper integration with raw meal preheating and heat recovery from the kiln flue gases. The adoption of entrained flow gas-solid reactors is particularly suitable for this Calcium Looping configuration, as because in such reactors the same very fine raw material can be used for clinker production $(\mathrm{CaO})$ and for $\mathrm{CO}_{2}$ sorption without additional milling requirements. Moreover, entrained flow reactors are already commonly used in cement plants.

\section{Implementation}

The core activity of the CLEANKER project is the design, construction and operation of a $\mathrm{CaL}$ demonstration system including the entrained-flow carbonator (the $\mathrm{CO}_{2}$ absorber) and the entrained-flow oxyfuel calciner (the sorbent regenerator). This demonstration system, connected to the Buzzi Unicem kiln of the Vernasca cement plant (Italy), will capture the $\mathrm{CO}_{2}$ from a portion of the flue gases of the kiln, using as $\mathrm{CO}_{2}$ sorbent the same raw meal that is used for clinker production.

Other activities include: (i) screening of different raw meals to assess their properties as $\mathrm{CO} 2$ sorbent, (ii) reactors and process modelling, (iii) scale-up study, (iv) economic analysis, (v) life cycle assessment, (vi) CO2 transport, storage and utilization study, (vii) demonstration of the complete value chain, including mineral carbonation of waste ash with the $\mathrm{CO} 2$ captured in the pilot system, (viii) exploitation study for the demonstration of the technology.

In the early engineering phase, the flow sheet had a simple and clear structure. The design ended with a 693 drawings and revision level "O" of the flow sheet. In the current third year, the installation of 110 tons equipment (plus 40 tons refractory), 38 major pipes, 78 expansion joints for heat compensation and 189 instrument items, has been assembling according to the layout shown in Fig. 2 that, together with the rendering of the demo plant, shows the simplified scheme of the layout. 

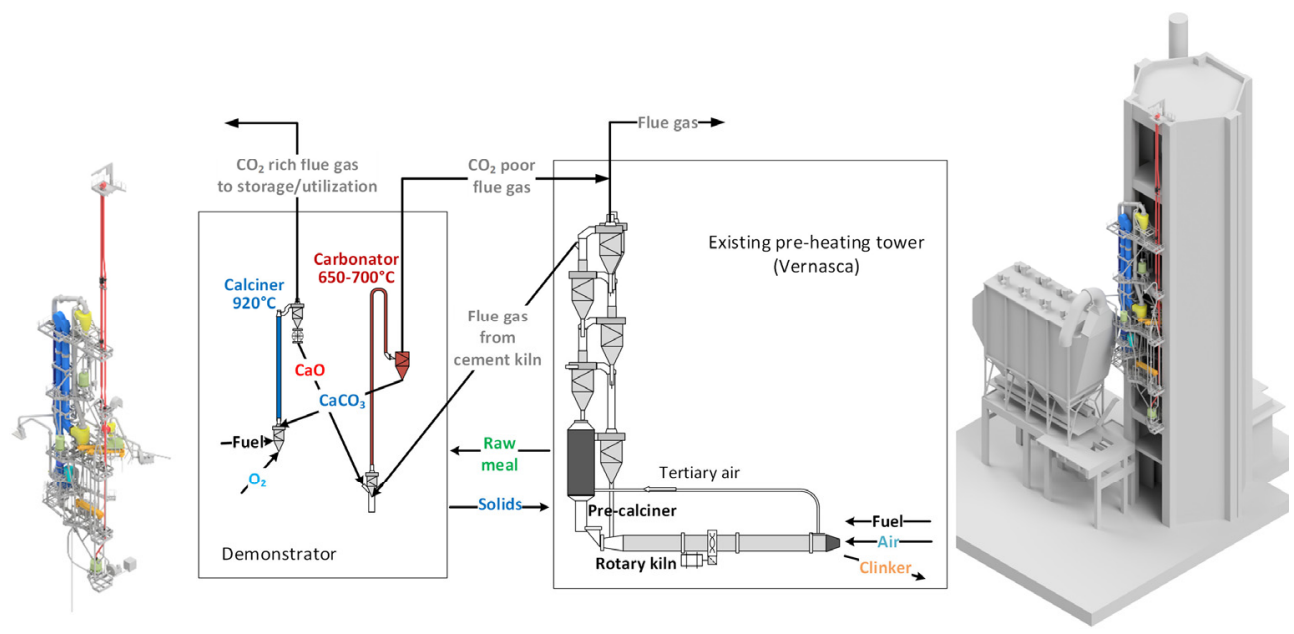

Fig. 2: Rendering of the demo system and layout of the simplified scheme

The main objectives reached so far were the finalisation of pilot engineering, the equipment construction and almost final erection (90\%) of the demo system. COVID-19 emergency caused a sudden interruption of the electrical works required to complete the plant construction. After a suspension of few months, works are now ongoing and the demo plant is almost completed: the advancement of the erection activity is higher than $90 \%$, with the residual works being related to the installation of electrical and instrumentation equipment. In the meantime, control strategies, safety analysis and risk analysis were also assessed, giving to the operators the possibility to carry out the next experimental campaigns in a safe and flexible way, exploiting all the peculiar features of the CaL demo plant.

\section{Demo system and experimental campaigns planning}

The erection of the pilot plant started in summer 2019 (Fig. 3) and the demo system should have been commissioned in April 2020. Due to the COVID situation, it will be commissioned in August and then demonstrated by means of several short and long steadystate tests (carried out during summer and autumn 2020), with the aim of optimizing the operational parameters governing the $\mathrm{CO}_{2}$ capture process and of bringing the integrated CaL technology at TRL7. 


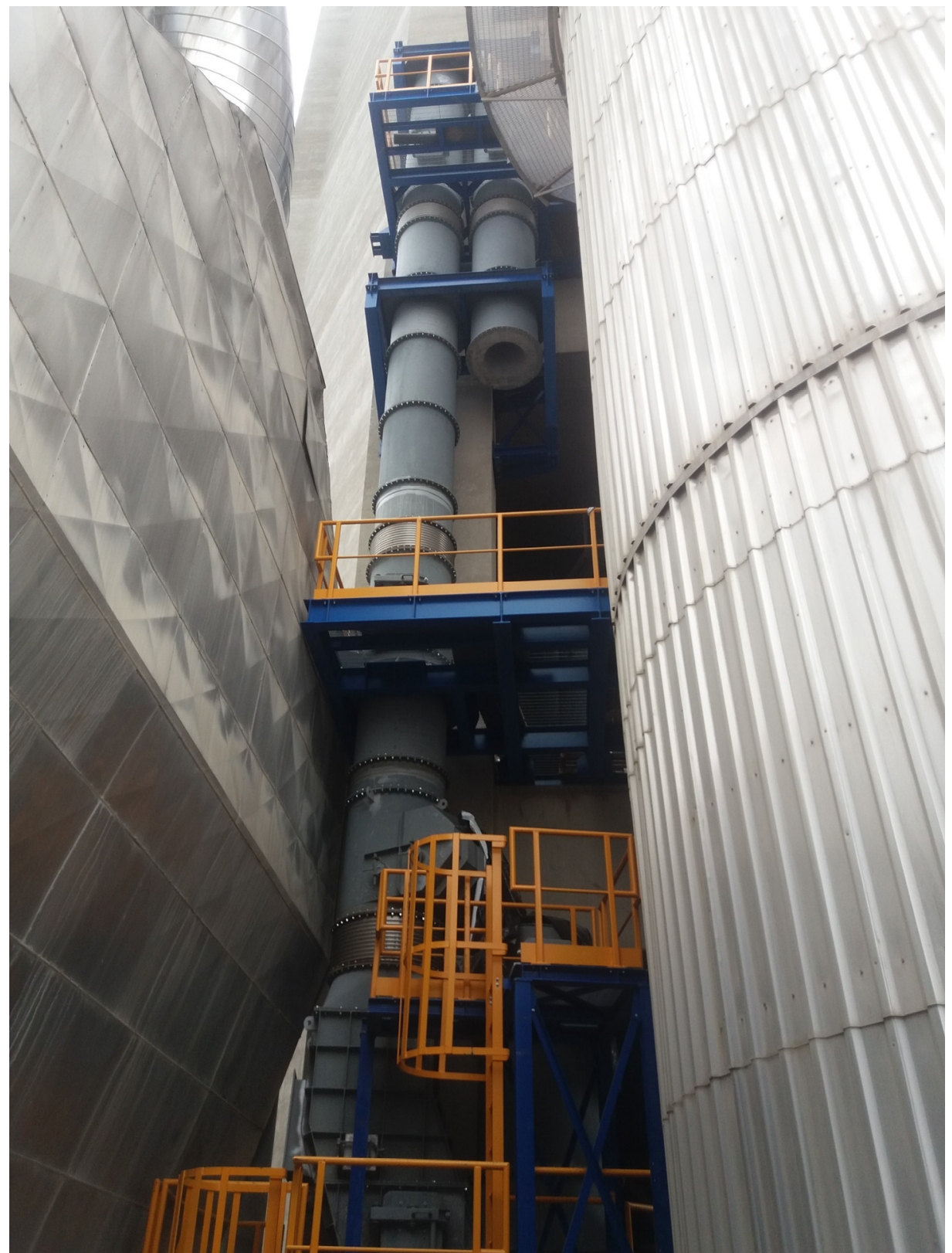

Fig. 3: Mechanical erection - CLEANKER calciner

The pilot plant and the conventional kiln operations will be deeply integrated: the CaL calciner will be fed by the same kind of raw meal used in the kiln for producing clinker, whereas the carbonator will treat the effluents provided by combustion and calcination occurring in the rotary kiln and in the pre-calciner. The CaL calciner will be fired in a recirculated oxy-fuel combustion mode, where a heavy fuel oil will be burnt with oxygen and a fraction of the $\mathrm{CO}_{2}$-rich exhausts will be recirculated to control the oxidant composition. Before being recycled to the $\mathrm{CaL}$ calciner inlet, this $\mathrm{CO}_{2}$-rich stream will be properly cooled in a regenerative riser-cyclone stage, designed to preheat the fresh raw meal-based sorbent fed to the pilot, minimizing the additional fuel supplied to run the 
calcium looping process. In the carbonator, the amount of sorbent will be tuned either by increasing the raw meal exchanged with the $\mathrm{CaL}$ calciner or by internally recycling a fraction of sorbent from the carbonator outlet to the inlet. First short campaigns will be carried out by specialized Buzzi operators (assisted by some CLEANKER partners such as, Politecnico di Milano, Laboratorio Energia e Ambiente Piacenza, University of Stuttgart and VDZ) to test the process performances as a function of the type of raw meal, the amount of sorbent (solid to gas ratio in the carbonator) and the carbonation/calcination operating temperatures.

The experimental activity will prove the stability and the effectiveness of the process by running over hundreds of hours the optimal experimental configuration, capable of achieving a constant carbon capture rate higher than $90 \%$. Besides the continuous monitoring of process temperatures, flow rates and gas compositions, the experimental campaigns will be supported post-processing sorbent analysis, in order to evaluate the capture capacity of the raw meal and the extent of side reactions (i.e. belite formation). During the last year of the project, test results will be exploited to validate simulation models and to improve the future scale-up and the design of an industrial size CaL plant.

\section{Conclusions}

The ultimate objective of CLEANKER in fact, is studying, designing, and demonstrating the integrated Calcium-looping process for $\mathrm{CO} 2$ capture in cement plants. Up to now, Calcium Looping has been extensively analysed and experimentally proven in the dual circulating fluidized bed configuration, used as a post-combustion capture system in coal-fired power plants and in cement plants. In general, there is a high-temperature solid looping cycles network (https://ieaghg.org/networks/high-temperature-solid-loopingcycles-network), a network to promote further development and scale-up of processes for $\mathrm{CO} 2$ capture which involve solid looping cycles operating at elevated temperatures. The network is progressively expanding participation beyond the research community, businesses, plant designers and equipment suppliers as the technology moves rapidly through pilot and industrial demonstration towards full-scale commercial deployment. In this view, CLEANKER project represents a concrete example of industrial applications.

The CLEANKER system is based on entrained flow reactors, and exploits the conventional raw meal as $\mathrm{CO} 2$ carrier. Some fundamental objectives reached so far are:

-Design and construction of the novel EF CaL reactor demo system, specifically developed for being integrated to cement plants, is almost completed. The pilot plant has the flexibility of testing a large combination of different $\mathrm{CaL}$ operating parameters. The design experience and the challenges solved during the erection stages can be exploited for the design and construction of a full scale system;

-A detailed screening on the properties of different raw meals as $\mathrm{CO} 2$ sorbent was achieved in laboratory facilities (drop tube reactors, Thermal Gravimetric Analysis); experimental trials were used to the develop reaction sub-models;

-Simulation models specifically developed for the integrated CaL configuration, including the kinetics of the raw meal based sorbent, have already been implemented and will be validated when the short and long trials on the demo plat will be carried out;

- $\mathrm{CO}_{2}$ transport, storage and utilization study. In addition, mineralization of Estonian waste oil shale ash with experimental tests in the Vernasca plant site will be performed.

Experimental campaigns to validate the technology are expected to start in SummerAutumn 2020. 
This project has received funding from the European Union's Horizon 2020 research and innovation programme under grant agreement no 764816 (CLEANKER).

\section{References}

